\title{
Reactive power control to enhance the VSC-HVDC system performance under faulty and normal conditions
}

\author{
Mohamed S. Ghayad ${ }^{1}$, Niveen M. Badra ${ }^{2}$, Almoataz Y. Abdelaziz ${ }^{3}$, Mahmoud A. Attia ${ }^{4}$ \\ ${ }^{1,2}$ Department Physics and Engineering Mathematics, Faculty of Engineering, Ain Shams University, Egypt \\ ${ }^{3}$ Faculty of Engineering \& Technology, Future University in Egypt, Cairo, Egypt \\ ${ }^{4}$ Department of Electrical Power and Machines, Faculty of Engineering, Ain Shams University, Egypt
}

\begin{tabular}{l} 
Article Info \\
\hline Article history: \\
Received Oct 1, 2018 \\
Revised Apr 23, 2019 \\
Accepted May 12, 2019 \\
\hline
\end{tabular}

\section{Keywords:}

GSA algorithm

Optimization

Reactive power

SCA algorithm

VSC- HVDC

\begin{abstract}
This paper studied the reactive power control of the voltage source converters based high-voltage direct current system (VSC-HVDC). PI (proportional \& integration) controller was used in this work to enhance the dynamic response of the system. Gravitational search algorithm (GSA) and sine cosine algorithm (SCA) are used to get optimal parameters of the PI controller. GSA algorithm is based on the gravity law for Newton while SCA depends on mathematical model based on cosine and sine functions. These algorithms have an efficient global Search capability. The VSC-HVDC is exposed to different disturbances for checking the controller robustness. First disturbance was applying three phase faults on the system. While the second one was applying a step change in AC voltage. Finally, Applying step change in regulators reference values. Simulation results proved the controller superiority also verified the enhancement of the system dynamic response.
\end{abstract}

Copyright $@ 2019$ Institute of Advanced Engineering and Science. All rights reserved.

\section{Corresponding Author:}

Mohamed S.Ghayad,

Department Physics and Engineering Mathematics,

Ain Shams University,

Abdo Basha square, Abbassia, Cairo11517, Egypt.

Email: M.elsayed@eng.asu.edu.eg

\section{INTRODUCTION}

The electrical power is generated, transmitted and distributed as an AC power. This power is transmitted from the generators to the customer via transmission lines. There are two kinds of transmission lines used for high voltages and long distance: HVDC and High Voltage Alternating Current (HVAC). HVDC transmission has many merits such as, it can transmit bulk power over long distances with minimum cost because it depend on two conductors only, it has minimum losses because there is no skin effect and it can connect two systems with different frequencies without the need of synchronization. Nowadays there are many projects use HVDC transmission especially in connecting different countries to exchange electrical power. There are two types of HVDC systems.

a. Classical HVDC System: in this system the thyristor technology used to convert AC to DC (rectifier process) and from DC to AC (inverter process). The thyristors are connected in series construction to build up thyristor valve. The operating frequency for this valve is the network frequency (50 or 60) hertz (Hz) [1].

b. VSC based HVDC System: in this system the semiconductor used to the conversion process is the GTO (Gate Turn-Off Thyristor) or the IGBT (Insulated Gate Bipolar Transistor). The converters operate using Pulse Width Modulation (PWM) control technique [2].

In this paper VSC-based HVDC system is used due to its multiple advantages such as:

a. The converters are able to independently control the reactive power and active power. 
b. Ability of connecting passive networks which has no local power generation or weak AC networks.

c. It has faster dynamic response due to increased switching frequency (PWM).

d. The dc link voltage polarity remains constant during reversing the power flow process.

The converters of VSC-HVDC system can be controlled through a closed loop consists of control units and PI controller which has strong robustness and simple structure. Therefor it is necessary to find suitable values of PI parameters for the steady operation of the system. Controlling of active and reactive power is one of the important requirements of the HVDC system. In classical HVDC system the reactive power is always a demand from the converter. Therefor it is supplied by sources of reactive power which installed at converter stations or by grid [3]. On the other hand the converter of VSC- HVDC has ability to supply or absorb reactive power into or from the grid so this system can control the reactive power of the AC systems at both ends independently while the flow of active power is balanced between these ends [4].

The aim of this paper is finding optimal parameters of PI using optimization methods to control the reactive power in the system during any disturbance in order to get better and faster dynamic response. The disturbances used in this paper are three phase fault, AC voltage sag and step change in regulators reference values. Conventional methods such as Smith and pole assignment methods are used to set PI parameters [5]. Due to the difficulty of getting the transfer function of VSC HVDC system, these methods will not useful. Jing Yong use estimation method to set gains of PI controller using PSCAD/EMTDC software, but the estimation method has no scientific foundation [6].

A simplex algorithm is presented for optimizing the parameters of PI controllers [7]. Modeling of the VSC- HVDC system for optimal power flow (OPF) solution using Newton-Raphson method [8]. Recently there are new methods for optimization called meta heuristic methods which has ability to get the optimal value of any parameter near global value fast. Genetic algorithm is used to get the parameters of controller [9]. Artificial bee colony and mine blast algorithms are applied to get optimal gain of VSC- HVDC system with sliding mode control [10]. In this paper the meta heuristic methods used are (GSA \& SCA) for getting optimal values of the gains.

The rest of paper is organized as follows: In Section 2, Modeling and description of the system. Control System is introduced in section 3. Optimization methods are presented in Section 4. Simulation results are provided in Section 5 and Section 6 includes conclusion.

\section{MODELING AND DESCRIPTION OF SYSTEM}

The VSC based HVDC transmission system between two AC systems consists of two converter stations (one is as a rectifier and the other is inverter) connected by a DC cable. Figure 1 shows the single line diagram of VSC-HVDC. In this paper VSC-HVDC system model which is established in MATLAB Simulink is used.This system is designed to transmit $200 \mathrm{MW}$ at $100 \mathrm{KV}$ DC. Figure 2 shows the Simulink model of the system.

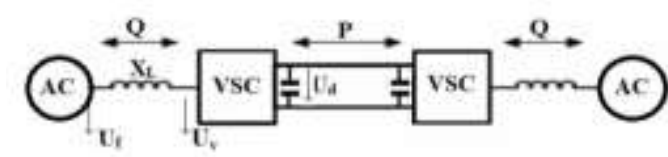

Figure 1. SLG for VSC-HVDC

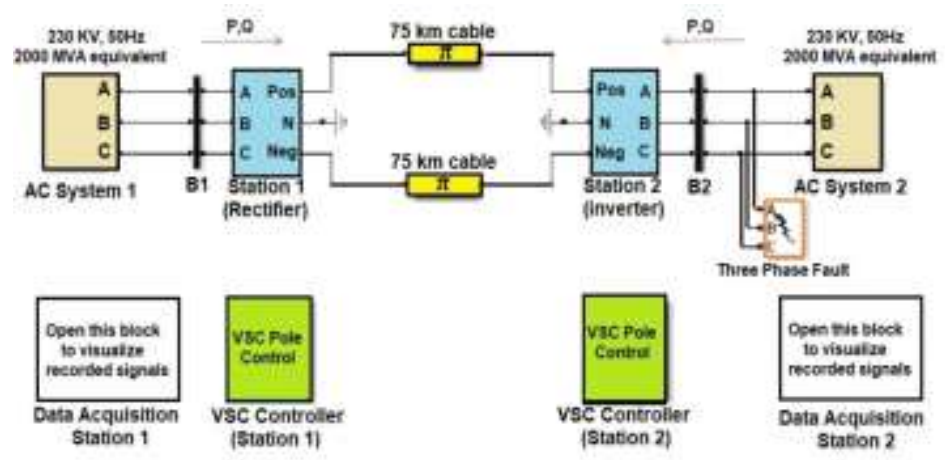

Figure 2. Simulink model of VSC-HVDC 
This model consists of:

a. Two identical AC System (1 \&2) and their ratings are $2000 \mathrm{MVA}, 230 \mathrm{kV}$ and $50 \mathrm{~Hz}$.

b. Transformers: the function of the transform is stepping down the ac system voltage from $230 \mathrm{kV}$ to 100 $\mathrm{kV}$ to be proper for each converter.

c. AC Filters: Shunt high pass filters with $40 \mathrm{MVAR}$ are installed after the transformers on the AC system side to eliminate high order harmonics.

d. Phase Reactors: These reactors are connected in series between the transformer and the station converter and their values are $0.15 \mathrm{pu}$. They are used for controlling reactive and active power by regulating currents which passes through them and used to reduce the high frequency harmonics.

e. Converters stations: There are two converters one acts as a rectifier and the other as an inverter and the semiconductor used is IGBT with antiparallel diode. There is a controller circuit in each station to reach controlled pulses to IGBT.

f. DC Capacitors : These capacitors are installed on the DC side and the size of them depend on the required DC voltage. The function of these capacitors is reducing the voltage ripples on the DC side and used as energy storage to control the the power flow and they have value of 70 micro farad.

g. DC Cables: The two converters stations are connected through DC cables. The power is transmitted through two pi sections of length $75 \mathrm{~km}$. The construction of station 1 is shown in Fig 3 and it is identical for station 2 .

The construction of station 1 is shown in Figure 3 and it is identical for station 2

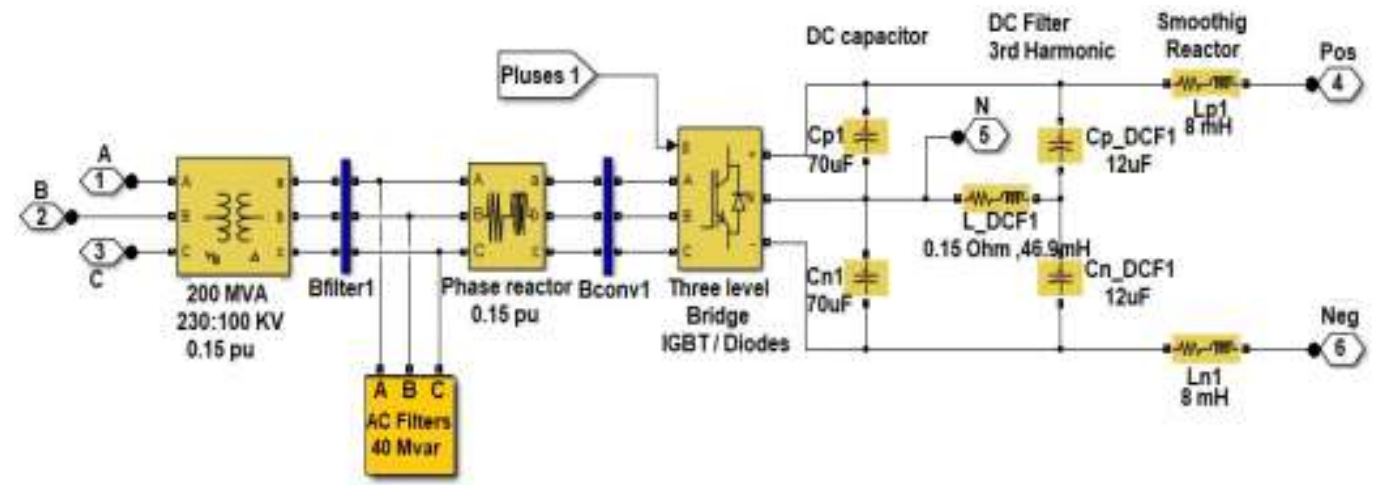

Figure 3. Construction of station 1

\section{CONTROL SYSTEM}

The controller design of converter 1 and converter 2 are identical. The two controllers are independent with no communication between them. These are used to control active power ( $\mathrm{P}$ ), reactive power( $\mathrm{Q})$ and DC voltage $\left(\mathrm{U}_{\mathrm{d}}\right)$ in the system. Figure 4 shows an overview diagram of the control system and its connection with the main circuit.

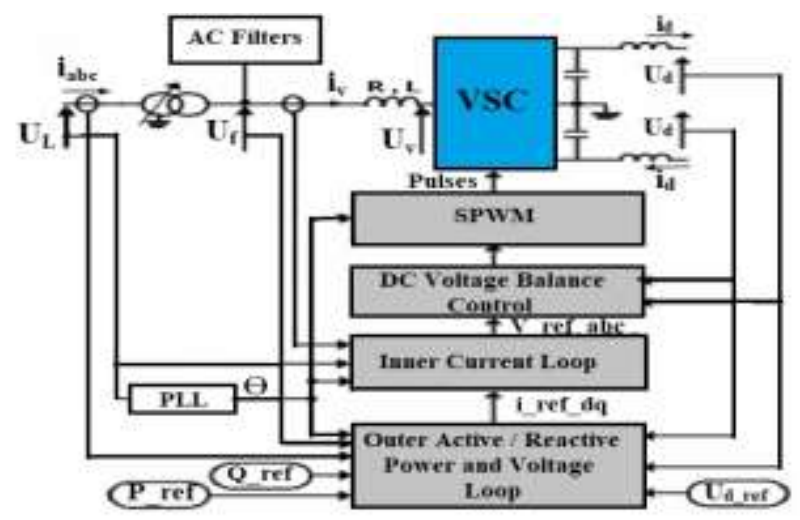

Figure 4. Overview diagram blocks of the VSC control system 
The control circuit consists of main blocks as follow:

\subsection{The phase locked loop (PLL) block}

The function of this block is to calculate the transformation angle $(\Theta)$ which used in the (d-q transformation). This is done by measuring the frequency of the system and provides this angle. In steady state, $\sin (\Theta)$ is inphase with the fundamental positive sequence of ( $\square$-component) and phase A of the point of common coupling voltage (Uabc).

\subsection{Outer active and reactive power and voltage loop}

The DC voltage and active power are controlled by the controlling the power angle $(\delta)$ and the reactive power control is done by controlling the modulation index (which is the ratio between the fundamental output voltage of converter and the DC voltage). The instantaneous active and reactive power of the inverter can be written in terms of the $\mathrm{d}$-q components of the voltage and the current as follows:

$P=\frac{3}{2}\left(U_{\mathrm{fd}} i_{\mathrm{vd}}+U_{\mathrm{fq}} i_{\mathrm{vq}}\right)$

$Q=\frac{3}{2}\left(-U_{\mathrm{fd}} i_{\mathrm{vq}}+U_{\mathrm{fq}} i_{\mathrm{vd}}\right)$

If the reference of the dq-frame is chosen such that the (q-component) of the voltage is being very small and can be neglected (ULq $\approx 0$ ) then in (1) and (2) indicate that the reactive and the active power are proportional to the $\mathrm{q}$ and $\mathrm{d}$ component of the current respectively. Therefore, it is possible to control the DC voltage, the active power and the reactive power by controlling the current components $i_{v d}$ and $i_{v q}$ respectively. The active and reactive power and voltage loop contains the outer loop regulators that compute the reference value of the current vector $\left(\mathrm{I}_{\text {ref_dq }}\right)$ which is the input to the inner current loop. Also it contains PI controller with a feed forward control to increase the speed response.

\subsection{Inner current loop}

This loop is used to track the reference current vector with a feed forward scheme to achieve fast control of the controller at disturbances and load changes. The equation after applying KVL for each phase is:

$$
U_{\mathrm{f}}-U_{\mathrm{v}}=L \frac{\mathrm{di}_{\mathrm{v}}}{\mathrm{dt}}+R \mathrm{i}_{\mathrm{w}}
$$

During unbalanced operation of equation [3], the voltage drop equations over the impedance ( + $\mathrm{j} \omega \mathrm{L}$ ) holds for positive and negative sequence voltages and currents. The voltages drops are described by the differential in (4) as follow:

$$
\frac{\mathrm{d}}{\mathrm{dt}}\left[\begin{array}{c}
i_{\mathrm{waZ}} \\
i_{\mathrm{vbz}} \\
i_{\mathrm{wcZ}}
\end{array}\right]=\left[\begin{array}{ccc}
-\frac{R}{L} & 0 & 0 \\
0 & -\frac{R}{L} & 0 \\
0 & 0 & -\frac{R}{L}
\end{array}\right]\left[\begin{array}{l}
i_{\mathrm{vaz}} \\
i_{\mathrm{vbz}} \\
i_{\mathrm{wcZ}}
\end{array}\right]-\left[\begin{array}{ccc}
\frac{1}{L} & 0 & 0 \\
0 & \frac{1}{L} & 0 \\
0 & 0 & \frac{1}{L}
\end{array}\right]\left[\begin{array}{l}
\mathrm{U}_{\mathrm{vaZ}} \\
\mathrm{U}_{\mathrm{vbz}} \\
\mathrm{U}_{\mathrm{vcZ}}
\end{array}\right]+\left[\begin{array}{ccc}
\frac{1}{L} & 0 & 0 \\
0 & \frac{1}{L} & 0 \\
0 & 0 & \frac{1}{L}
\end{array}\right]\left[\begin{array}{c}
\mathrm{U}_{\mathrm{faZ}} \\
\mathrm{U}_{\mathrm{fbz}} \\
\mathrm{U}_{\mathrm{fcZ}}
\end{array}\right]
$$

Where $Z=(p)$ for positive sequence and $(n)$ for negative sequence. Equation (4) can be transformed to the $\alpha \beta$-frame as follow in (5):

$$
\frac{\mathrm{d}}{\mathrm{dt}}\left[\begin{array}{l}
\mathrm{i}_{\mathrm{vaZ}} \\
\mathrm{i}_{\mathrm{v} \beta \mathrm{Z}}
\end{array}\right]=\left[\begin{array}{cc}
-\frac{R}{\mathrm{~L}} & 0 \\
0 & -\frac{R}{\mathrm{~L}}
\end{array}\right]\left[\begin{array}{l}
\mathrm{i}_{\mathrm{vaZ}} \\
\mathrm{i}_{\mathrm{v} \beta \mathrm{Z}}
\end{array}\right]-\left[\begin{array}{cc}
\frac{1}{\mathrm{~L}} & 0 \\
0 & \frac{1}{\mathrm{~L}}
\end{array}\right]\left[\begin{array}{l}
\mathrm{U}_{\mathrm{vaZ}} \\
\mathrm{U}_{\mathrm{v} \beta \mathrm{Z}}
\end{array}\right]+\left[\begin{array}{cc}
\frac{1}{\mathrm{~L}} & 0 \\
0 & \frac{1}{\mathrm{~L}}
\end{array}\right]\left[\begin{array}{c}
\mathrm{U}_{\mathrm{faZ}} \\
\mathrm{U}_{\mathrm{f} \beta \mathrm{Z}}
\end{array}\right]
$$

Equation (5) can be further transformed to the rotating dq-frame as follow in (6) \& (7).

$$
\begin{aligned}
& \frac{\mathrm{d}}{\mathrm{dt}}\left[\begin{array}{l}
\mathrm{i}_{\mathrm{wdp}} \\
\mathrm{i}_{\mathrm{wqp}}
\end{array}\right]=\left[\begin{array}{cc}
-\frac{R}{\mathrm{~L}} & \omega \\
-\omega & -\frac{R}{\mathrm{~L}}
\end{array}\right]\left[\begin{array}{l}
\mathrm{i}_{\mathrm{wdp}} \\
\mathrm{i}_{\mathrm{wqp}}
\end{array}\right]-\left[\begin{array}{cc}
\frac{1}{\mathrm{~L}} & 0 \\
0 & \frac{1}{\mathrm{~L}}
\end{array}\right]\left[\begin{array}{l}
\mathrm{U}_{\mathrm{wdp}} \\
\mathrm{U}_{\mathrm{wqp}}
\end{array}\right]+\left[\begin{array}{ll}
\frac{1}{\mathrm{~L}} & 0 \\
0 & \frac{1}{\mathrm{~L}}
\end{array}\right]\left[\begin{array}{l}
\mathrm{U}_{\mathrm{fdp}} \\
\mathrm{U}_{\mathrm{fqp}}
\end{array}\right] \\
& \frac{\mathrm{d}}{\mathrm{dt}}\left[\begin{array}{l}
\mathrm{i}_{\mathrm{wdn}} \\
\mathrm{i}_{\mathrm{wqn}}
\end{array}\right]=\left[\begin{array}{cc}
-\frac{R}{\mathrm{~L}} & -\omega \\
\omega & -\frac{R}{\mathrm{~L}}
\end{array}\right]\left[\begin{array}{l}
\mathrm{i}_{\mathrm{wdn}} \\
\mathrm{i}_{\mathrm{wqn}}
\end{array}\right]-\left[\begin{array}{cc}
\frac{1}{\mathrm{~L}} & 0 \\
0 & \frac{1}{\mathrm{~L}}
\end{array}\right]\left[\begin{array}{l}
\mathrm{U}_{\mathrm{wdn}} \\
\mathrm{U}_{\mathrm{wqn}}
\end{array}\right]+\left[\begin{array}{ll}
\frac{1}{\mathrm{~L}} & 0 \\
0 & \frac{1}{\mathrm{~L}}
\end{array}\right]\left[\begin{array}{l}
\mathrm{U}_{\mathrm{fdn}} \\
\mathrm{U}_{\mathrm{fqn}}
\end{array}\right]
\end{aligned}
$$



follow:

The positive and negative sequence voltages of the VSC side are obtained from the last equations as

$$
\begin{aligned}
& \mathrm{U}_{\mathrm{wdp}}=\mathrm{U}_{\mathrm{fdp}}-R \mathrm{i}_{\mathrm{vdp}}+(\omega \mathrm{L}) \mathrm{i}_{\mathrm{vqp}}-\mathrm{L} \frac{\mathrm{d}}{\mathrm{dt}} \mathrm{i}_{\mathrm{vdp}} \\
& \mathrm{U}_{\mathrm{wdp}}=\mathrm{U}_{\mathrm{fdp}}-R \mathrm{i}_{\mathrm{vdp}}+(\omega \mathrm{L}) \mathrm{i}_{\mathrm{vqp}}-\mathrm{L} \frac{\mathrm{d}}{\mathrm{dt}} \mathrm{i}_{\mathrm{vdp}} \\
& \mathrm{U}_{\mathrm{wdn}}=\mathrm{U}_{\mathrm{fdn}}-R \mathrm{i}_{\mathrm{vdn}}-(\omega \mathrm{L}) \mathrm{i}_{\mathrm{vqn}}-\mathrm{L} \frac{\mathrm{d}}{\mathrm{dt}} \mathrm{i}_{\mathrm{vdn}} \\
& \mathrm{U}_{\mathrm{wqn}}=\mathrm{U}_{\mathrm{fqn}}-R \mathrm{i}_{\mathrm{vqn}}+(\omega \mathrm{L}) \mathrm{i}_{\mathrm{vdn}}-\mathrm{L} \frac{\mathrm{d}}{\mathrm{dt}} \mathrm{i}_{\mathrm{vqn}}
\end{aligned}
$$

The mean voltages over the sample period $\mathrm{k}$ to $\mathrm{k}+1$ are obtained by integrating (8), (9), (10) and (11) from $(k)$ Ts to $(k+1) T s$ and dividing by Ts (where Ts is the sampling time).

$$
\begin{aligned}
& \overline{\mathrm{U}}_{\mathrm{wdp}}=\overline{\mathrm{U}}_{\mathrm{fdp}}-R \overline{\mathrm{i}}_{\mathrm{wdp}}+(\omega \mathrm{L}) \overline{\mathrm{i}}_{\mathrm{wqp}}-\frac{\mathrm{L}}{\mathrm{T}_{\mathrm{s}}}\left\{\mathrm{i}_{\mathrm{wdp}}(\mathrm{k}+1)-\mathrm{i}_{\mathrm{wdp}}(\mathrm{k})\right\} \\
& \overline{\mathrm{U}}_{\mathrm{wqp}}=\overline{\mathrm{U}}_{\mathrm{fqp}}-R_{\mathrm{wqp}}-(\omega \mathrm{L}) \overline{\mathrm{i}}_{\mathrm{wdp}}-\frac{\mathrm{L}}{T_{\mathrm{s}}}\left\{\mathrm{i}_{\mathrm{wqp}}(\mathrm{k}+1)-\mathrm{i}_{\mathrm{wqp}}(\mathrm{k})\right\} \\
& \overline{\mathrm{U}}_{\mathrm{wdn}}=\overline{\mathrm{U}}_{\mathrm{fdn}}-R \overline{\mathrm{i}}_{\mathrm{wdp}}-(\omega \mathrm{L}) \overline{\mathrm{i}}_{\mathrm{wqn}}-\frac{\mathrm{L}}{\mathrm{T}_{\mathrm{s}}}\left\{\mathrm{i}_{\mathrm{wdn}}(\mathrm{k}+1)-\mathrm{i}_{\mathrm{wdn}}(\mathrm{k})\right\} \\
& \overline{\mathrm{U}}_{\mathrm{wqn}}=\overline{\mathrm{U}}_{\mathrm{fqn}}-R_{\mathrm{wqn}}+(\omega \mathrm{L}) \overline{1}_{\mathrm{wdn}}-\frac{\mathbb{L}}{T_{x}}\left\{\mathrm{i}_{\mathrm{wqn}}(\mathrm{k}+1)-\mathrm{i}_{\mathrm{wqn}}(\mathrm{k})\right\}
\end{aligned}
$$

Equations (16-19) are obtained by assuming constant network voltage and linear current during one sample period Ts.

$$
\begin{aligned}
& \mathrm{U}_{\mathrm{wdp}}(\mathrm{k}+1)=\mathrm{U}_{\mathrm{fdp}}(\mathrm{k})-\frac{\mathrm{R}}{2}\left\{\mathrm{i}_{\mathrm{wdp}}(\mathrm{k}+1)+\mathrm{i}_{\mathrm{wdp}}(\mathrm{k})\right\}+\frac{\omega \mathrm{L}}{2}\left\{\mathrm{i}_{\mathrm{wqp}}(\mathrm{k}+1)+\mathrm{i}_{\mathrm{wqp}}(\mathrm{k})\right\}-\frac{\mathrm{L}}{T_{\mathrm{s}}}\left\{\mathrm{i}_{\mathrm{wdp}}(\mathrm{k}+1)-\mathrm{i}_{\mathrm{wdp}}(\mathrm{k})\right\} \\
& \mathrm{U}_{\mathrm{wqp}}(\mathrm{k}+1)=\mathrm{U}_{\mathrm{fqp}}(k)-\frac{R}{2}\left\{\mathrm{i}_{\mathrm{vqp}}(\mathrm{k}+1)+\mathrm{i}_{\mathrm{vqp}}(\mathrm{k})\right\}-\frac{\omega \mathrm{L}}{2}\left\{\tilde{\mathrm{i}}_{\mathrm{vdp}}(\mathrm{k}+1)+\tilde{\mathrm{i}}_{\mathrm{vdp}}(\mathrm{k})\right\}-\frac{\mathrm{L}}{\mathrm{T}_{\mathrm{s}}}\left\{\tilde{\mathrm{i}}_{\mathrm{wqp}}(\mathrm{k}+1)-\mathrm{i}_{\mathrm{vqp}}(\mathrm{k})\right\} \\
& \mathrm{U}_{\mathrm{wdn}}(\mathrm{k}+1)=\mathrm{U}_{\mathrm{fdn}}(k)-\frac{R}{2}\left\{\mathrm{i}_{\mathrm{wdn}}(\mathrm{k}+1)+\mathrm{i}_{\mathrm{vdn}}(\mathrm{k})\right\}-\frac{\omega \mathrm{L}}{2}\left\{\mathrm{i}_{\mathrm{vqn}}(\mathrm{k}+1)+\tilde{\mathrm{i}}_{\mathrm{wqu}}(\mathrm{k})\right\}-\frac{\mathrm{L}}{\tau_{\mathrm{g}}}\left\{\mathrm{i}_{\mathrm{vdn}}(\mathrm{k}+1)-\tilde{\mathrm{i}}_{\mathrm{vdn}}(\mathrm{k})\right\} \\
& \mathrm{U}_{\mathrm{wqn}}(\mathrm{k}+1)=\mathrm{U}_{\mathrm{fqn}}(\mathrm{k})-\frac{\mathrm{R}}{2}\left\{\mathrm{i}_{\mathrm{wqn}}(\mathrm{k}+1)+\mathrm{i}_{\mathrm{wqn}}(\mathrm{k})\right\}+\frac{\omega \mathrm{L}}{2}\left\{\mathrm{i}_{\mathrm{vdn}}(\mathrm{k}+1)+\mathrm{i}_{\mathrm{wvdn}}(\mathrm{k})\right\}-\frac{\mathrm{L}}{\mathrm{T}_{\mathrm{g}}}\left\{\mathrm{i}_{\mathrm{vqn}}(\mathrm{k}+1)-\mathrm{i}_{\mathrm{vqn}}(\mathrm{k})\right\}
\end{aligned}
$$

The control is based on (16-19), where the voltages and currents at time $(\mathrm{k}+1)$ are thus equal to the reference values at time $(\mathrm{k})$.

\subsection{DC voltage balance control}

This block is used to keep the voltage DC side of the three-level bridge balanced (i.e., equal pole voltages) in steady-state. It is possible to find small deviations between the pole voltages due to changes of converter current or due to nonlinearity on shortage of precision in the execution of the pulse width modulated bridge voltage. Figure 5 shows a high-level diagram of the simulink model for VSC controller.

\section{OPTIMIZATION METHODS}

The word of optimization stands for the process of getting optimal value for the parameters of any system to minimize or maximize its objective function.

The optimization problems can be classified into many categories based on if they are discrete or continuous, mono or multi-objective, constrained or unconstrained and dynamic or static. An overview of some conventional methods and meta heuristic techniques which can be used in electrical power optimization problems is presented in [11]. 


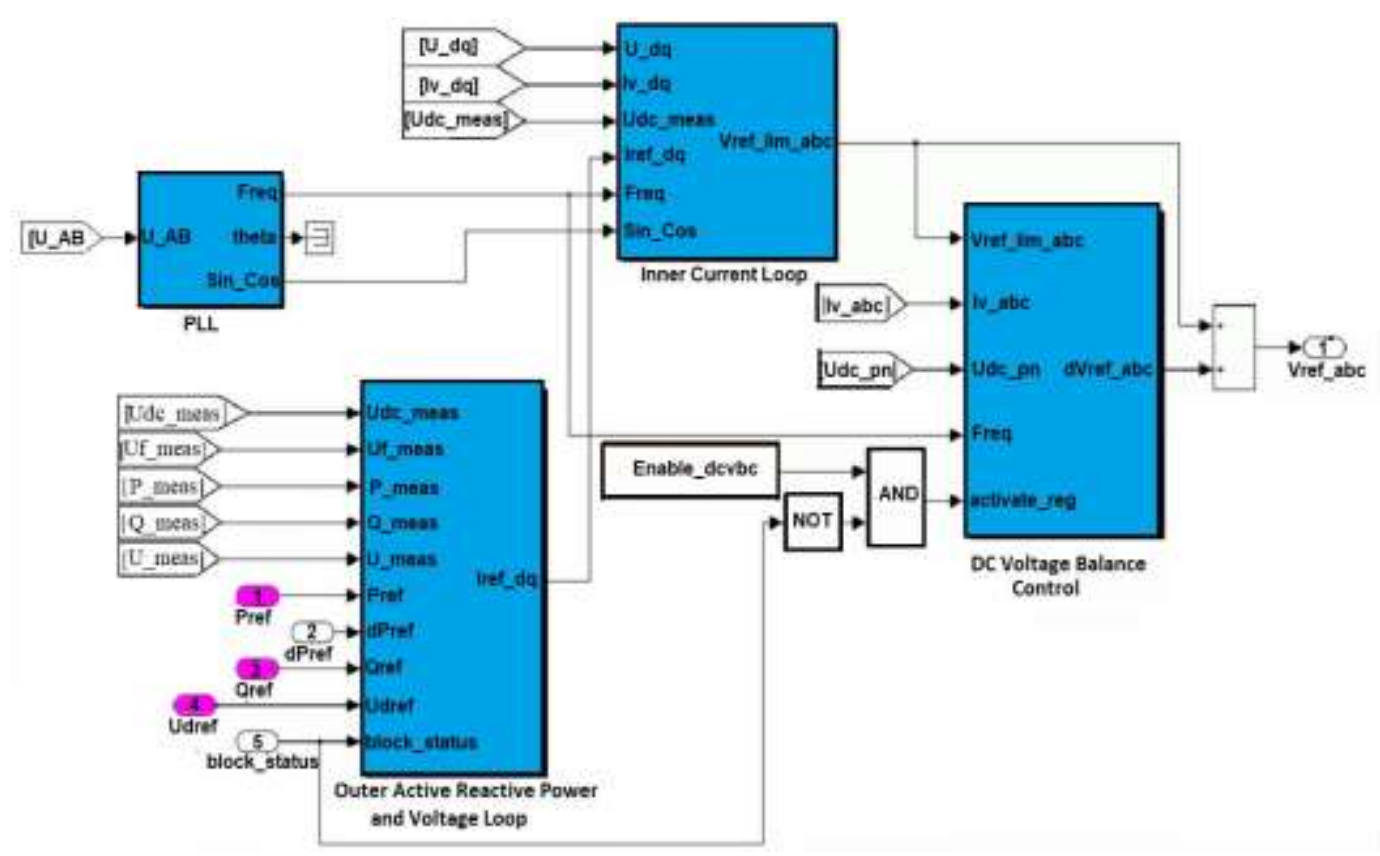

Figure 5. Simulink model of control circuit

The conventional optimization algorithms do not give a suitable solution because the search space increases exponentially with the problem size. Meta heuristic optimization algorithms look to the optimization problems as black boxes [12]. This means that getting the mathematical models is not necessary because such optimization methods only vary the inputs (parameters) and notice the outputs of the system for minimizing and maximizing its outputs. These methods try to seek good solutions (near global) for the problem search space. These methods are motivated from evolutionary phenomena, behavior of creatures, physical laws and human-related concepts. Some of the famous algorithms in each of these subclasses are presented as follows:

a) Behavior of creatures-based techniques: Particle Swarm Optimization (PSO) [13], Ant Colony Optimization [14] (ACO) and Artificial Bee Colony (ABC) algorithm [15].

b) Evolutionary techniques: Differential Evolution (DE) [16] and Genetic Algorithms (GA) [17].

c) Physics rules -based techniques: Colliding Bodies Optimization (CBO) [18], Gravitational Search Algorithm (GSA) [19] and Black Hole (BH) [20].

d) Human-related techniques: Mine Blast Algorithm (MBA) [21], League Championship Algorithm (LCA) [22] and Teaching-Learning-Based Optimization (TLBO) [23].

In this paper a two meta heuristic search algorithms will be used which has less computational time, relative high accuracy and less parameters requirements. The first method is called Gravitational Search Algorithm (GSA) and the second is called Sine Cosine Algorithm (SCA). The two methods are explained briefly in the following sections:

\subsection{Gravitational search algorithm (GSA)}

This algorithm is depending on gravity law for Newton which says "The attraction force between the particles is inversely proportional to the square of the distance between them and directly proportional to the product of their masses".

In this algorithm, agents are considered as particles and their performance is measured by their masses i.e. the better solution is corresponding to the heavy masses. All these particles attract each other by the attraction force and this force causes a movement of all particles towards the particles with heavier masses while heavy masses move more slowly than lighter ones. As the time passes, all masses will be attracted by the heaviest mass. This mass will present an optimum solution in the search space. The principle of GSA is explained in details in [19]. Figure 6 shows the steps of operation in each iteration as a flow chart. 


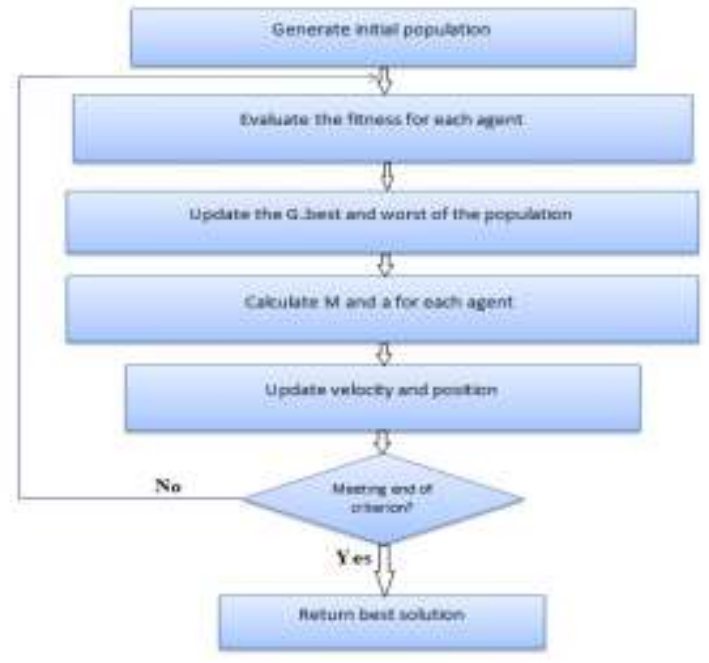

Figure 6. Flow chart of GSA

\subsection{Sine cosine algorithm:}

The optimization process in this algorithm starts the by a set of random solution then it begans to update the position of this solution. The updating position is done according to:

$$
\begin{aligned}
& X_{i}^{t+1}=X_{i}^{t}+r_{1} \times \sin \left(r_{2}\right) \times\left|r_{3} P_{i}^{t}-X_{i}^{t}\right| \\
& X_{i}^{t+1}=X_{i}^{t}+r_{1} \times \cos \left(r_{2}\right) \times\left|r_{3} P_{i}^{t}-X_{i}^{t}\right|
\end{aligned}
$$

Where $\mathbf{X}_{\mathbf{i}}^{\mathbf{t + 1}}$ is the position of new solution, $\mathbf{X}_{\mathbf{i}}^{\mathbf{t}}$ is the position of current solution in t-iteration and $\mathbf{r}_{\mathbf{1}}$, $\mathbf{r}_{2}, \mathbf{r}_{3}$ are random numbers [24]. The switching between the two equations is based on random variable $\left(r_{4}\right)$. The recent equations are the reason behind the name of this algorithm. As the iteration counter increases, the ranges of cosine and sine functions are updated to emphasize exploitation of the search space. The algorithm stops the optimization process when the iteration counter becomes higher than the maximum number of iterations. Figure 7 shows the flow chart of the algorithm.

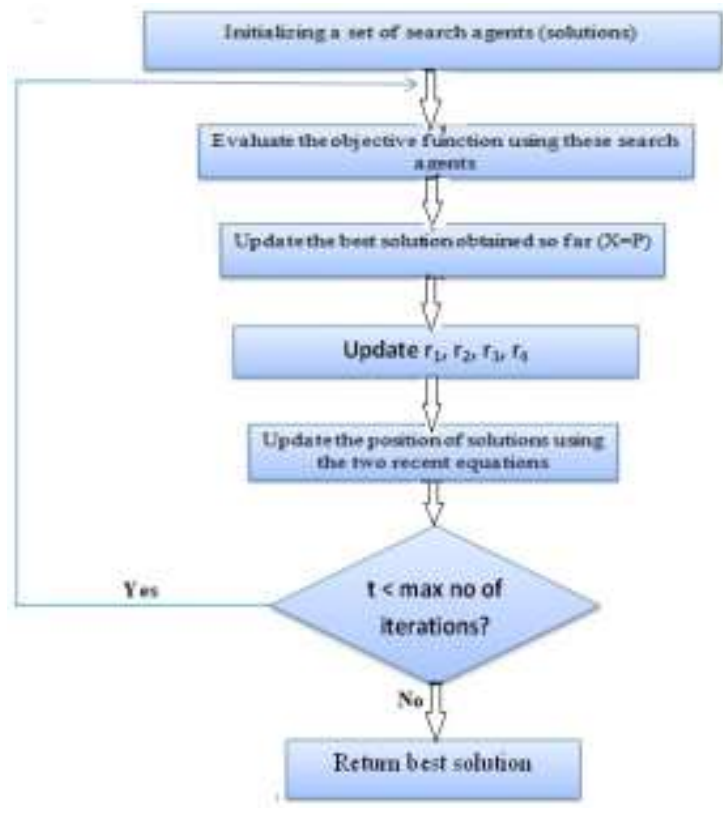

Figure 7. Flow chart of SCA 


\section{SIMULATION RESULTS}

The objective of this section is checking the dynamic reactive power response of the HVDC system and trying to improve this response via tuning the PI controller parameters using optimization methods. To check the dynamic response the system is exposed to different disturbances such as three phase fault, AC voltage sag and step change in reference values. Then observing the reactive power response with respect to the reference in each case. This section consists of two parts, The first part explain type of parameters and the values of the default and optimal parameters after applying optimization methods, while the second part conclude the comparison between the reactive power dynamic response of default system and optimized system.

\section{Part 1: Getting optimal parameters using GSA and SCA method}

In this part the GSA and SCA are used to tune the reactive power PI controller when the system is exposed to severe three phase fault at system. There are six control parameters $\left(\mathrm{K}_{\mathrm{I} \_}\right.$regulator, $\mathrm{k}_{\mathrm{P} \_}$control and $\mathrm{k}_{\mathrm{I} \_}$contol for station 1 and $\mathrm{K}_{\mathrm{I} \_ \text {regulator, }} \mathrm{k}_{\mathrm{P} \_ \text {control and }} \mathrm{k}_{\mathrm{I} \_}$contol for station 2) which used to control reactive power. $\mathrm{K}_{\mathrm{I} \_}$regulator used to keep the value of measured reactive power with the desired range. $\mathrm{k}_{\mathrm{P} \_}$control and $\mathrm{k}_{\mathrm{I} \_}$contol are used to settle the value of the measured reactive power fast. The objective function is minimizing the error between the measured and reference value of reactive power. Both methods will try randomly to get minimum objective regardless the reactive power curve higher or lower than the reference. The range of these parameters is obtained by trial and error. For each method, it began to assume random solutions (values for the six paramters) within the given range, hence the system runs with these values. Then the fitness function (error between the measured reactive power value and refrence one) for each solution is computed. The minimum value of the fitness function indicates that these solutions can be best solutions. Using these solutions, the method began to generate new solutions and the previous cycle is repeated again until the no of iteration exceeds the maximum no of iteration (200 iteration). Range, default and optimal values are listed in Table 1.

Table 1.Values of Parameters

\begin{tabular}{lccccc}
\hline & Parameters & Range & Default & GSA & SCA \\
\hline Station 1 & $\mathrm{K}_{\mathrm{I} \text { regulator }}$ & $10-30$ & 20 & 10.8334 & 10.1433 \\
& $\mathrm{~K}_{\mathrm{P} \_ \text {control }}$ & $1-20$ & 3 & 2.5336 & 1.0326 \\
& $\mathrm{~K}_{\mathrm{I} \_ \text {control }}$ & $1-20$ & 3 & 5.2901 & 3.1119 \\
Station 2 & $\mathrm{K}_{\mathrm{I} \text { regulator }}$ & $10-30$ & 20 & 13.6473 & 21.6743 \\
& $\mathrm{~K}_{\mathrm{P} \_ \text {control }}$ & $1-20$ & 3 & 6.8214 & 1.6100 \\
& $\mathrm{~K}_{\mathrm{I} \_ \text {control }}$ & $1-20$ & 3 & 17.0372 & 9.4688 \\
\hline
\end{tabular}

\section{Part 2: Dynamic response comparison}

In this part a comparison between the default system and the optimized system in case of reactive power response is carried out. The system is exposed to three different disturbances as cases studies as follow:

Case 1: Applying three phase faults at the bus of AC system 2 at $1.5 \mathrm{sec}$ and clearing it after 0.25 sec. The reference value of reactive power $\left(\mathrm{Q}_{\mathrm{r}}\right)$ is $-0.1 \mathrm{pu}$. The reference value of active power is ramp value and reaches to $1 \mathrm{pu}$ after one second. The refrence value of DC voltage is $1 \mathrm{pu}$. Figure 8 shows the dynamic measured reactive power response $\left(\mathrm{Q}_{\mathrm{m}}\right)$ of the default system of system 2 which illustrates that the system takes long time to reach the reference value of reactive power after clearing the fault. Figure 9 shows the optimized system response using GSA which shows that the system reaches the reference value faster than the case of default system. Figure 10 shows the optimized system response using SCA which also has settling time less than the case of default system. Figure 11 shows the behaviour of all cases in one graph to get accurate comparison which confirms the result mentioned before that the settling time is improved and the settling time of GSA and SCA is almost $2.5 \mathrm{~s}$ and $2.9 \mathrm{~s}$ respectively while for default system is greater than three seconds. Also, it is noted that deviation from the reference value in SCA is smaller than deviation from the reference value in case of GSA. Figure 12 shows the response of active power of all cases in one graph. The response of default and GSA case and default case are similar but the response of SCA response is better than them because it has small devation from the reference. Figure 13 shows the dynamic response of DC voltage for all cases in one graph. It is noted that the default and GSA cases are better in response than SCA case. 


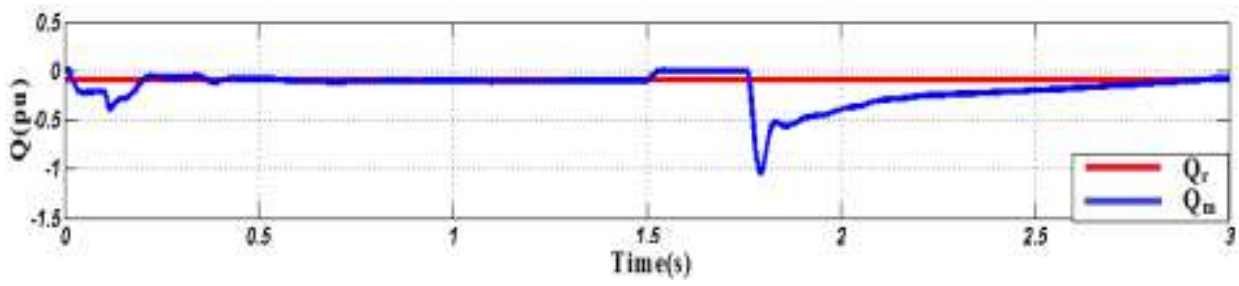

Figure 8. Reactive power response for default case

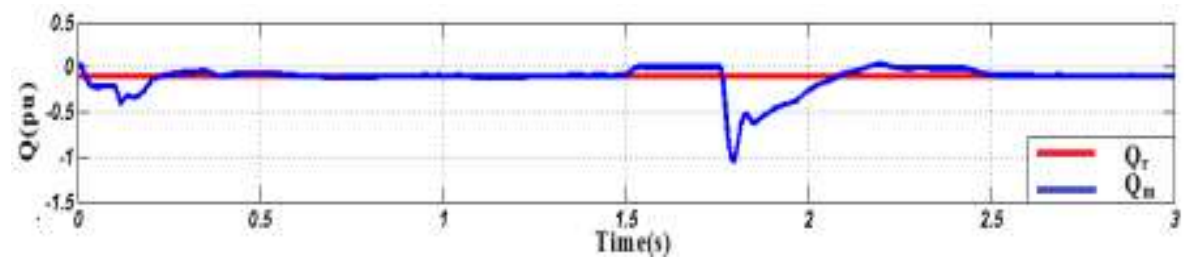

Figure 9. Reactive power response for GSA case

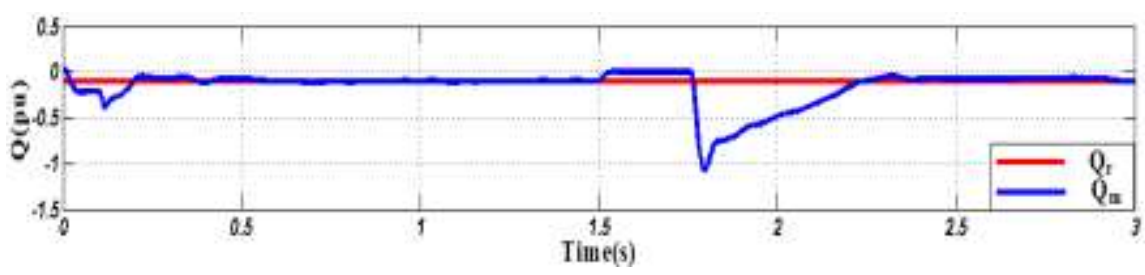

Figure 10. Reactive power response for SCA case

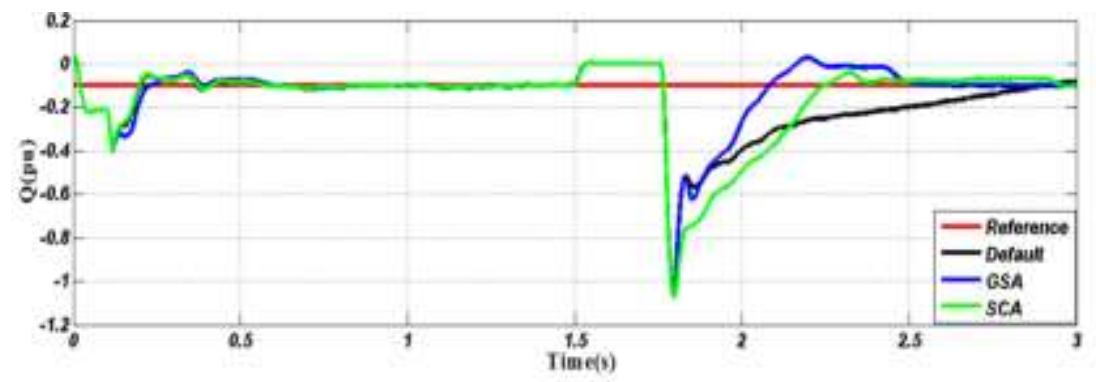

Figure 11. Reactive power response for all cases

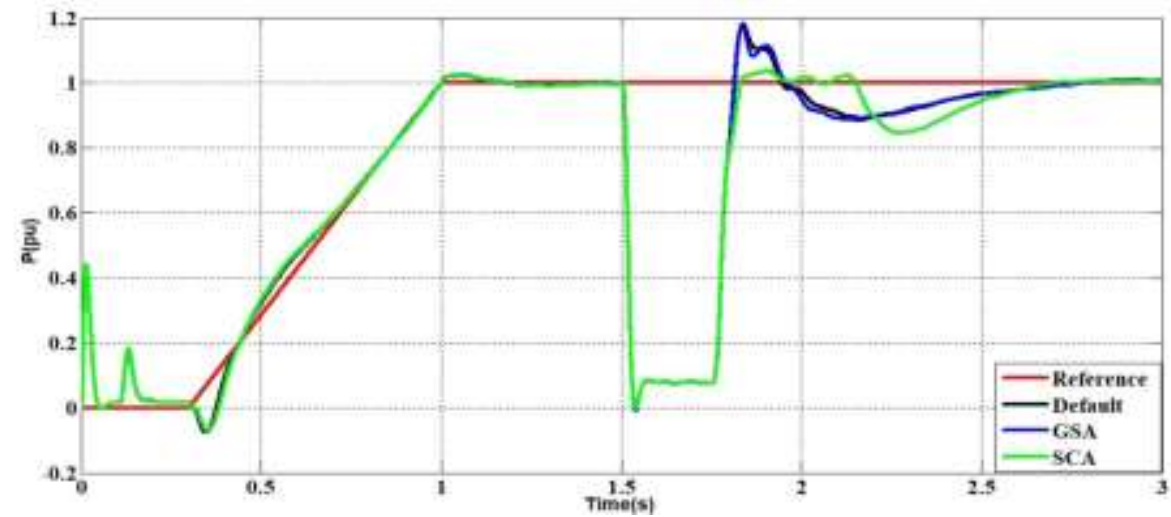

Figure 12. Active power response for all cases 


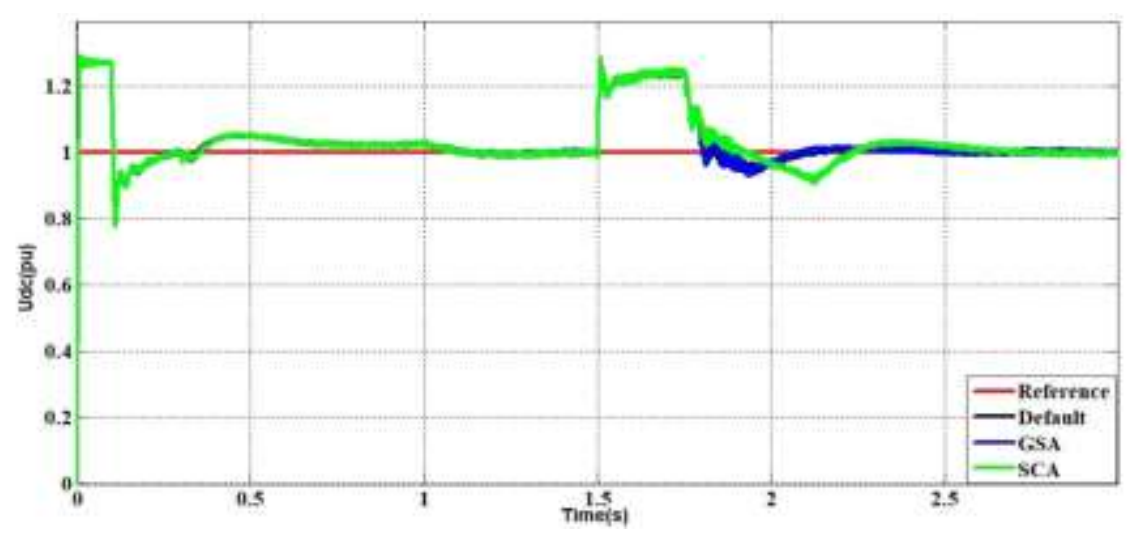

Figure 13. DC voltage response for all cases

Case 2: Applying a step change in AC voltage of system 1 and this is can be done by using three-Phase programmable voltage Source in system 1. The amplitude of AC voltage of system 1 is changed from 1 pu to $0.8 \mathrm{pu}$ at $1.5 \mathrm{~s}$ for $0.25 \mathrm{~s}$. Figure 14 shows the dynamic reactive power response of the default system of system 1 which illustrates that the deviation from the reference value is high during the voltage sag which reachs to $-0.48 \mathrm{pu}$. Figure 15 shows the optimized system response using GSA which has less deviation from the reference value than the default case during the voltage sag and this value reach to -0.4 pu. Figure 16 shows the optimized system response using SCA which has minimum deviation from the reference value compared with default and GSA cases during the voltage sag and its value reach -0.22 . Figure 17 shows the all previous cases in one graph which confirms the result mentioned before that SCA case has less reactive power deviation from the reference value. Figure 18 shows the dynamic response of active power which indicate that the response in case of SCA has less deviation from the reference value. Figure 19 shows the dynamic response of DC voltage which indicate tha the AC voltage sag has small effect on DC voltage and the response of all cases is similar.

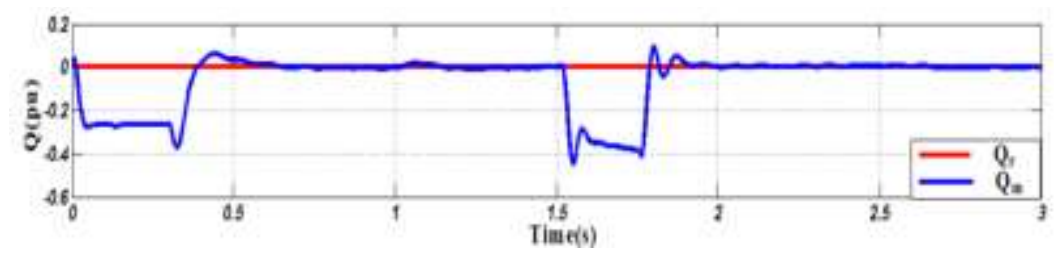

Figure 14. Reactive power response for default case

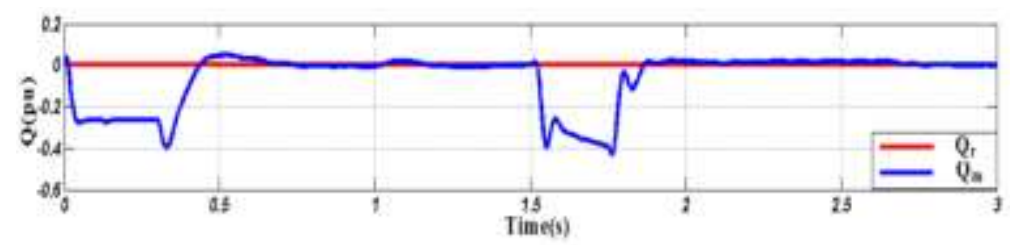

Figure 15. Reactive power response for GSA case

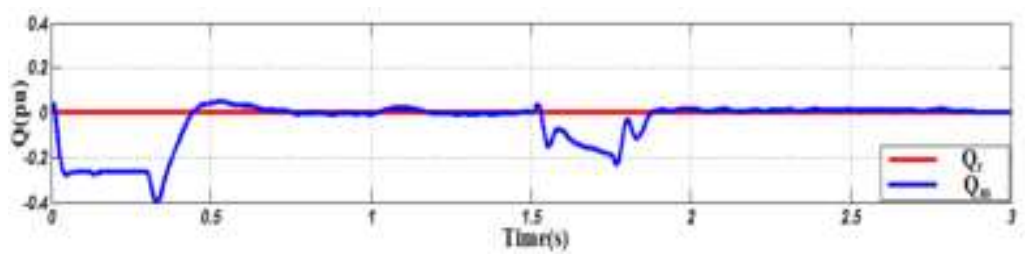

Figure 16. Reactive power response for SCA case 


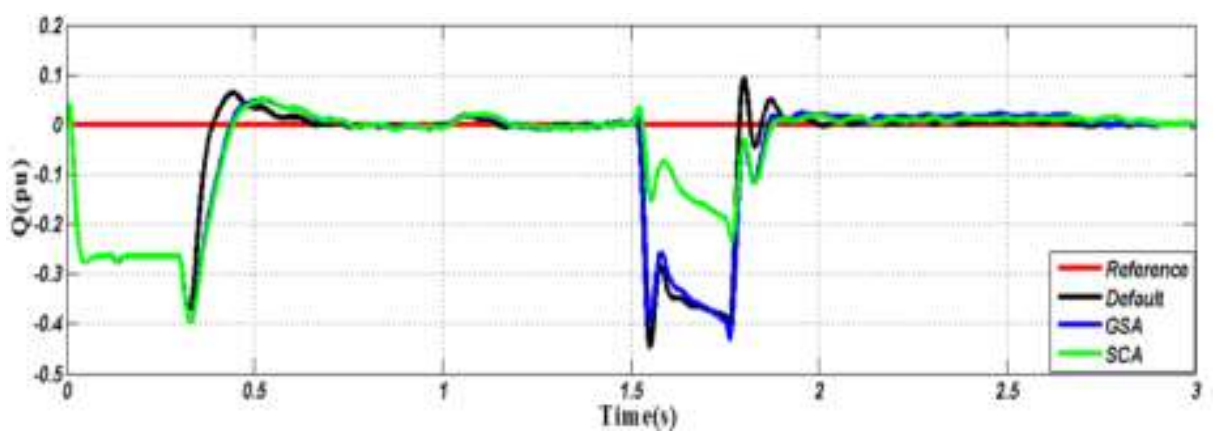

Figure 17. Reactive power response for all cases

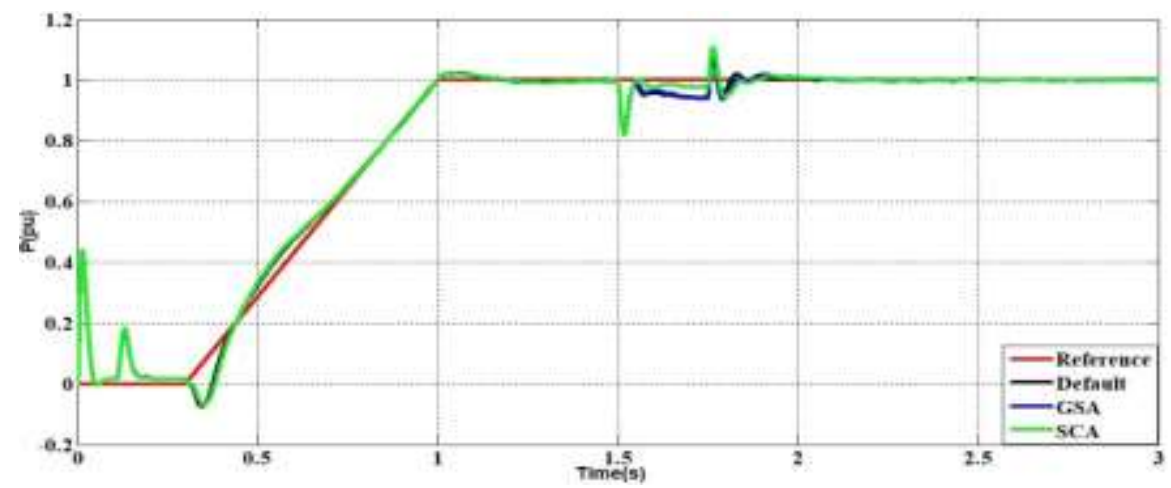

Figure 18. Active power response for all cases

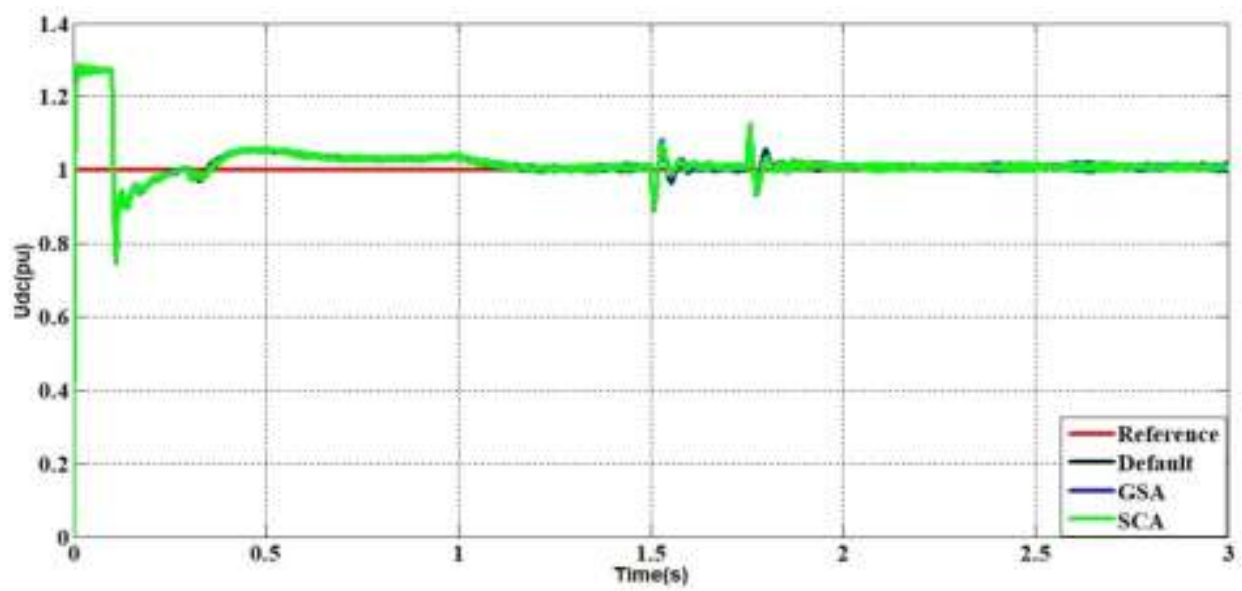

Figure 19. DC voltage response for all cases

Case 3: Applying step change in regulators reference values of active power, reactive power and DC voltage. After the system is reached to the steady state, the DC voltage reference is changed from 1 pu to 0.85 pu at $1.3 \mathrm{~s}$ then a step change in reactive power reference is applied at station 1 from 0 pu to $-0.1 \mathrm{pu}$ at $1.7 \mathrm{~s}$ last, a step change in active power reference is applied at station 1 from 1 pu to 0.9 pu at $2.3 \mathrm{~s}$. Figure 20 shows the dynamic reactive power response of the default system in station 1 which illustrates that the measured reactive power has high deviation from the reference value. Figure 21 shows the optimized system response has almost no deviation from the reference value of reactive power and it reaches the reference value fast. Figure 22 shows the optimized system response using SCA which also has very small deviation from the reference value but the settling time is greater than the case of GSA. Figure 23 shows the previous cases in one graph which confirms the result mentioned before that both GSA and SCA can improve the dynamic 
response during changing of regulators reference values. Figure 24 shows the dynamic response of active power which is similar in all cases but Figure 25 shows the dynamic response of DC voltage which is best in case of SCA and GSA as it reach to the reference value faster than the default case.

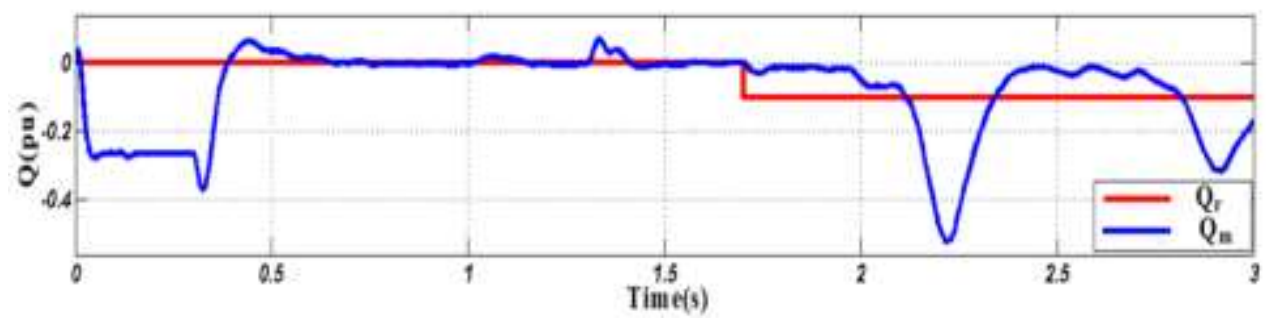

Figure 20. Reactive power response for default case

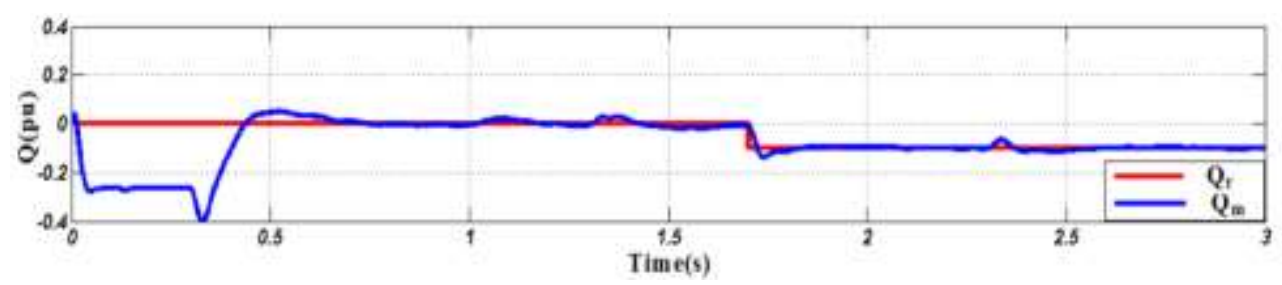

Figure 21. Reactive power response for GSA case

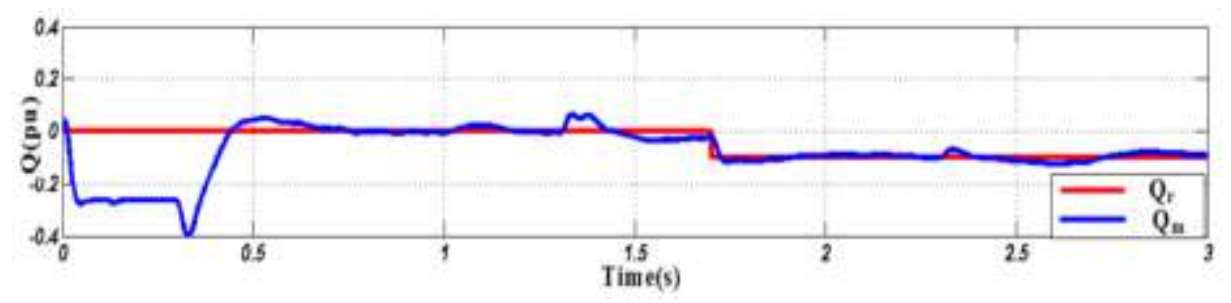

Figure 22. Reactive power response for SCA case

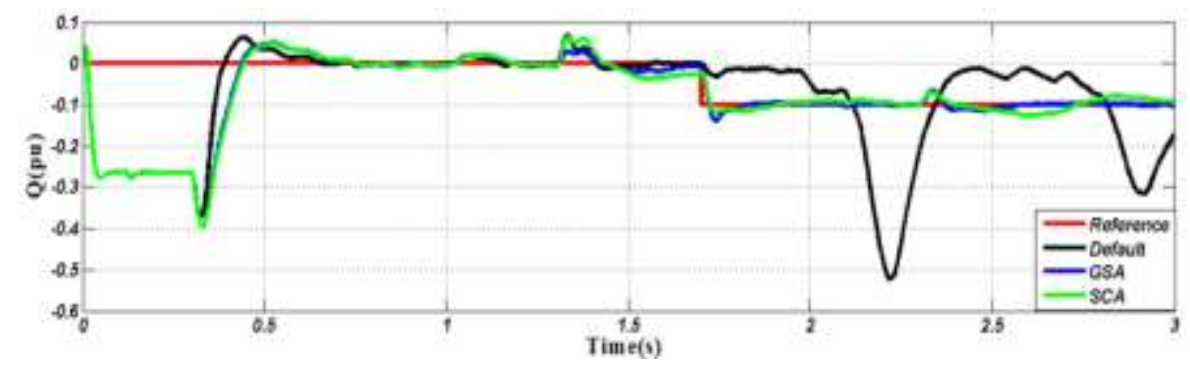

Figure 23. Reactive power response for all cases 


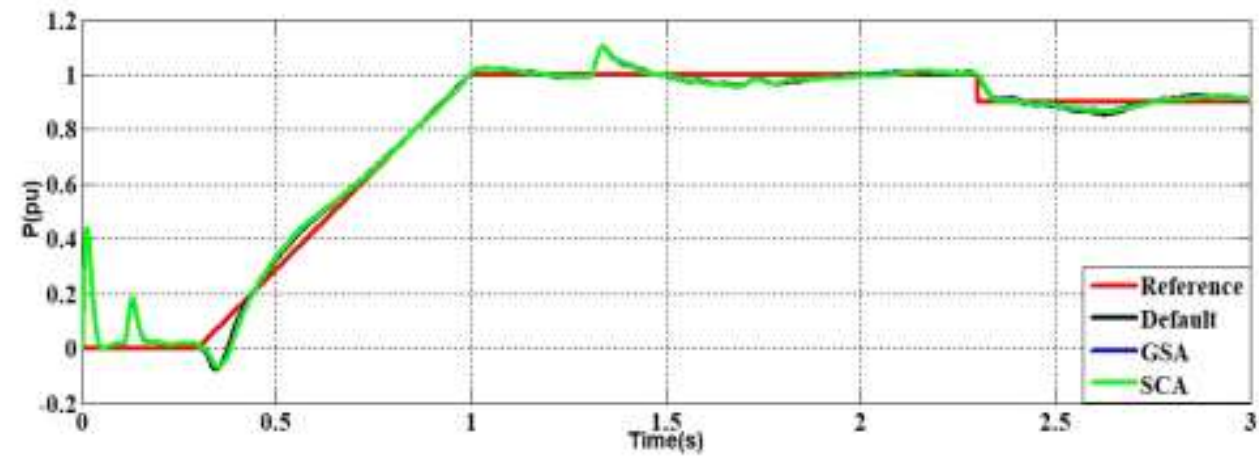

Figure 24. Active power response for all cases

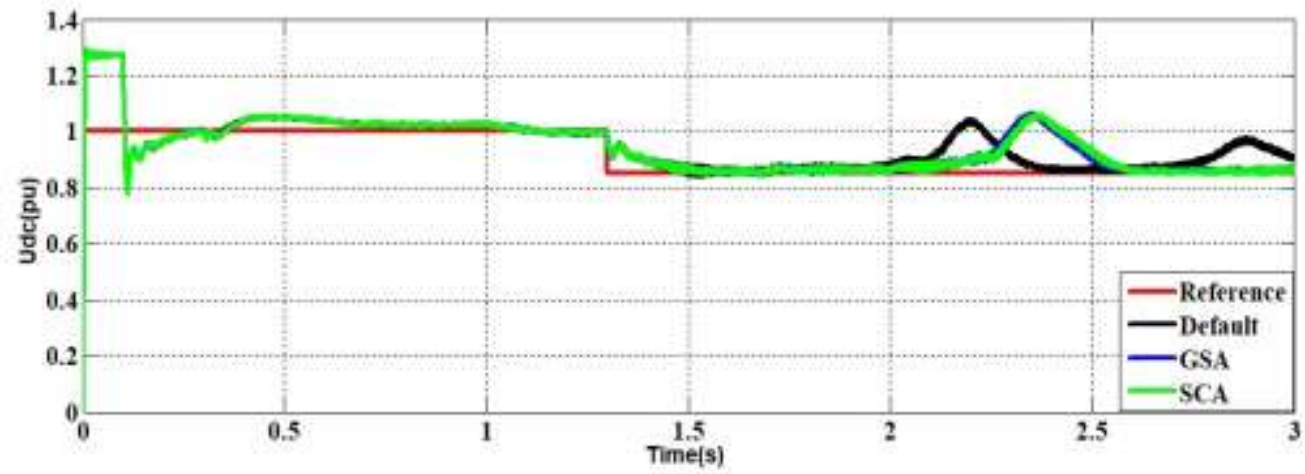

Figure 25. DC voltage response for all cases

\section{CONCLUSION}

The main purpose of this paper is improving the dynamic response of VSC HVDC transmission system during existing of any disturbance in it such as three phase fault, voltage sag of any AC grid and change in reference values. This is done by getting optimal gains valus of PI controllers to control reactive power. The optimization methods used to get optimal gains are GSA and SCA which Meta heuristic algorithms. Results proved that PI-SCA has better response than PI-GSA regarding reactive power deviation, but PI-GSA is has better performance in settling time.

\section{REFERENCES}

[1] Rudervall R, et al., "High voltage direct current (HVDC) transmission systems technology review paper" Presented at Energy Week 2000, Washington, DC, March 2000

[2] J.Holtz, "Pulse width modulation-a survey," PESC '92 Record. 23rd Annual IEEE Power Electronics Specialists Conference, Toledo, Spain, vol.1, pp. 11-18, 1992.

[3] Xiao Wang et al., "High Voltage Direct Current Transmission System Based on Voltage Source Converter," in IEEEPESC' 90 Record, vol.1, pp. 325-332.

[4] Michael P. Bahrman, et al., "Voltage Source Converter Transmission Technologies-The Right Fit for the Applications," in Proc. of IEEE-PES General Meeting, Toronto, Canada, pp. 1840-1847, July-2003.

[5] Liu Jinkun, "Advanced PID control and MATLAB simulation" Beijing: Publishing House of Electronics Industry, pp. 71-24, 2004.

[6] Jing Yong, et al., " Parameter estimation of regulators in Tian-Guang HVDC transmission system based on PSCAD/EMTDC," in Proc. 2002 International Conference on Power System Technology, Kunming, pp. 538-541, 2002.

[7] Zhao, et al., "Parameters Optimization of VSC-HVDC Control System Based on Simplex Algorithm," 2007 IEEE Power Engineering Society General Meeting, Tampa, FL, pp. 1-7, 2007.

[8] A. Pizano-Martinez, et al, "Modeling of VSC-Based HVDC Systems for a Newton-Raphson OPF Algorithm," in IEEE Transactions on Power Systems, vol. 22, no. 4, pp. 1794-1803, Nov. 2007.

[9] Hu Zhaoqing, Mao Chengxiong, Lu Jiming and Chen Man, "Genetic algorithm based control for VSC HVDC," 2005 IEEE/PES Transmission \& Distribution Conference \& Exposition: Asia and Pacific, Dalian, pp. 1-5, 2005. 
[10] Haitham S. Ramadan, et al.," Optimal gain scheduling of VSC-HVDC system sliding mode control via artificial bee colony and mine blast algorithms," IET Generation, Transmission \& Distribution journal, vol.12, pp. 661 - 669, 2018.

[11] Bansal R. C, "Optimization Methods for Electric Power Systems: An Overview," International Journal of Emerging Electric Power Systems, vol.2, 2005.

[12] S. Droste, et al., "Upper and lower bounds for randomized search heuristics in black-box optimization, " Theory of computing systems, vol. 39, pp. 525-544, 2006.

[13] R. C. Eberhart and J. Kennedy, "A new optimizer using particle swarm theory," in Proceedings of the sixth international symposium on micro machine and human science, pp. 39-43, 1995.

[14] M. Dorigo and M. Birattari, "Ant colony optimization," in Encyclopedia of machine learning, ed: Springer, pp. 3639,2010

[15] D. Karaboga and B. Basturk, "A powerful and efficient algorithm for numerical function optimization: artificial bee colony (ABC) algorithm," Journal of global optimization, vol.39, pp. 459- 471, 2007.

[16] R. Storn and K. Price,"Differential evolution-a simple and efficient heuristic for global optimization over continuous spaces," Journal of global optimization, vol.11, pp. 341-359, 1997.

[17] Saber M. Elsayed, et al, "A new genetic algorithm for solving optimization problems," Engineering Applications of Artificial Intelligence," Elsevier, vol.27, pp. 57-69, 1997.

[18] A.Kaveh, et al., "Colliding Bodies Optimization method for optimum discrete design of truss structures," Computers \& Structures, vol.139, pp. 43-53, 2014.

[19] E. Rashedi, H. Nezamabadi-Pour and S. Saryazdi, "GSA: a gravitational search algorithm," Information sciences, vol.179, pp. 2232-2248, 2009.

[20] A. Hatamlou, "Black hole: A new heuristic optimization approach for data clustering," Information sciences, vol. 222, pp. 175-184, 2013.

[21] A. Sadollah, et al, "Mine blast algorithm: A new population based algorithm for solving constrained engineering optimization problems," Applied Soft Computing, vol. 13, pp. 2592-2612, 2013.

[22] A. H. Kashan, "League Championship Algorithm (LCA): An algorithm for global optimization inspired by sport championships," Applied Soft Computing, vol. 16, pp. 171-200, 2013.

[23] R. V. RaoV. J. Savsani, and D. Vakharia, "Teaching-learning-based optimization: a novel method for constrained mechanical design optimization problems," Computer-Aided Design, vol.43, pp. 303-315, 2011.

[24] Seyedali Mirjalili, "SCA: A Sine Cosine Algorithm for Solving Optimization Problems," Knowledge-Based Systems, 2016, vol.96, pp. 120-133 